\title{
Effects of Cutting Time and Low-temperature Treatment of Rooted Cuttings on Stem Elongation and Leaf Number in Cultivars of Chrysanthemum morifolium
} Ramat.

\author{
Takahiro Tanigawa*, Toshihiro Kunitake, Takatoshi Matsuno, Asuka Yamada \\ and Takuro Suyama
}

Fukuoka Agricultural Research Center, Chikushino 818-8549, Japan

The effects of cutting time and low-temperature treatment of rooted cuttings on stem length and leaf number after planting were investigated in ten Chrysanthemum cultivars. Rooted cuttings propagated from mother plants on three different dates (September 30, November 10, and December 14) were planted two weeks after cutting and grown at constant temperatures of $20^{\circ} \mathrm{C}(7: 00-19: 00)$ and $12.5^{\circ} \mathrm{C}(19: 00-7: 00)$ under long days. In addition, rooted cuttings treated at $2.5^{\circ} \mathrm{C}$ for six weeks were planted on October 14 and November 24 . The ten cultivars could be divided into three groups based on the increased stem length (ISL) of the rooted cuttings five weeks after planting. In five of ten cultivars, the ISL of rooted cuttings decreased from the first cutting date to the second cutting date, and increased from the second cutting date to the third cutting date. In three of the ten cultivars, the ISL of rooted cuttings increased progressively from the first cutting date to the third cutting date. The ISL and increase in leaf number of the rooted cuttings receiving low-temperature treatment were higher than those of untreated cuttings in all cultivars. The capability for stem elongation is apparently reduced by either of two types of temperature-related factors; high temperature followed by low temperature, and the other is high temperature only or high temperature followed by a short period of low temperature.

Key Words: chrysanthemum, cutting time, low-temperature treatment, rosette.

\section{Introduction}

Using the usual methods of year-round cut flower production, Chrysanthemum morifolium Ramat. mother plants are prevented from flowering by growing under long-day conditions; vegetative shoots can then be removed at any time to produce rooted cuttings which, after a further period of vegetative growth under long days, are induced to flower by transfering to a short-day regime. Shoots (suckers) that emerge at the base of the flower stem in autumn without exposure to low temperatures are incapable of elongation during short days. Such shoots are in the rosette stage and, to induce stem elongation, mother plants must be exposed to an extended period of low temperature. In northern Europe, therefore, the low temperature requirement of modern

Received; February 13, 2008. Accepted; September 11, 2008.

Part of this paper was presented at the 2006 Autumn Meeting of the Japanese Society for Horticultural Science.

Tanigawa, T. and T. Kunitake contributed equally to this work.

* Corresponding author (E-mail: tanigawa@farc.pref.fukuoka.jp). year-round chrysanthemums has been eliminated through breeding and selection (Machin, 1978).

As some Japanese Chrysanthemum cultivars form rosettes in autumn and winter, cuttings cannot be taken from mother plants. Okada $(1959,1963)$ reported that low temperature or short day length was responsible for the induction of rosettes, and some cultivars formed rosettes when exposed to low temperatures of $10-15^{\circ} \mathrm{C}$, even under long-day conditions. Mason and Vince (1958) also reported that the absence of low temperatures, short days and low light intensities reduced internode length, and a certain combination of these factors might induce rosette-type growth. Moreover, the stem length and flower bud initiation of rooted cuttings declined in autumn and progressively recovered when mother plants were exposed to low temperatures from late autumn to winter (Tanigawa et al., 2007).

In 'Shuho no Chikara', one of the major cultivars selected for disbudding (standard) white cut flowers in Japan until the 1990s, the cuttings or rooted cuttings taken from mother plants were treated with low temperatures $\left(1-2^{\circ} \mathrm{C}\right)$ for several weeks to avoid 
reducting of stem elongation and delaying flowering when plant were grown at relatively low temperatures of $10-13^{\circ} \mathrm{C}$ in autumn and winter, and were grown at a minimum temperature of $15-17^{\circ} \mathrm{C}$. This type of cultivar often formed a secondary rosette at temperatures below $10^{\circ} \mathrm{C}$. The low temperature required for breaking the rosette stage varied among cultivars and summerflowering cultivars in general required less chilling than autumn-flowering cultivars (Okada, 1963).

However, some autumn-flowering cultivars that have been cultivated in recent years, e.g. 'Jinba', 'Seiko no Makoto', and 'Seiko no Aki', grow rapidly and flower well from November to January even at the relatively low temperatures of $13-15^{\circ} \mathrm{C}$. Mother plants of these cultivars do not form rosettes completely in an unheated greenhouse from autumn to winter. These findings indicate that Japanese autumn-flowering cultivars show a rosette tendency (expressing characteristics of a rosette stage) to varying degrees, and the reduction of stem length and leaf number of rooted cuttings taken from mother plants in late summer and autumn vary by cultivar. Thus, it is necessary to reconsider the characteristics of Japanese autumn-flowering cultivars that Okada $(1959,1963)$ and Konishi (1980) reported previously. In the study, we elucidated the effects of cutting time from mother plants and low-temperature treatment of rooted cuttings on stem length and leafing in ten autumn-flowering cultivars and evaluated the capability of stem elongation of these cultivars.

\section{Materials and Methods}

Mother plants of ten autumn-flowering cultivars of Chrysanthemum morifolium ('Chikushi no Tsuki', 'Jinba', 'Kanamaru Fuji', 'Miyoshino', 'Sanyo Ogon', 'Seiko Komei', 'Seiko no Aki', 'Seiko no Makoto', 'Shuho no Chikara', and 'Yukihime') were planted in a plastic greenhouse on June 24, 2005. The nights were interrupted from 22:00 to 3:00 using incandescent lamps $(75 \mathrm{~W}$, Toshiba Lighting and Technology Co., Kanagawa, Japan) to inhibit flower induction. Mother plants were trimmed moderately to prevent plants from growing above $20 \mathrm{~cm}$ tall. Tip cuttings from newly developed vegetative lateral shoots were taken on September 30, November 10, and December 14. These cuttings were rooted in volcanic soils (Bora-sands) by mist spraying in a greenhouse. After 14 days, rooted cuttings were planted in $1.0 \mathrm{~L}$ plastic pots containing a medium comprising a 4:4:2 mixture of paddy soil, leaf mold, and volcanic soil, respectively. In addition, rooted cuttings treated at $2.5^{\circ} \mathrm{C}$ for six weeks were planted in $1.0 \mathrm{~L}$ plastic pots on October 14 and November 24. There were five replicates per treatment on each date. Each pot received $4 \mathrm{mg}$ slow-release fertilizer $\left(\mathrm{N}: \mathrm{P}_{2} \mathrm{O}_{5}: \mathrm{K}_{2} \mathrm{O}\right.$ $=13: 16: 10$, Long Total Kaki 1-gou, 100-days-type, Chisso Asahi Hiryo Co, Tokyo, Japan) and was watered once every morning. After planting, pots were placed in a phytotron and were grown at constant temperatures of

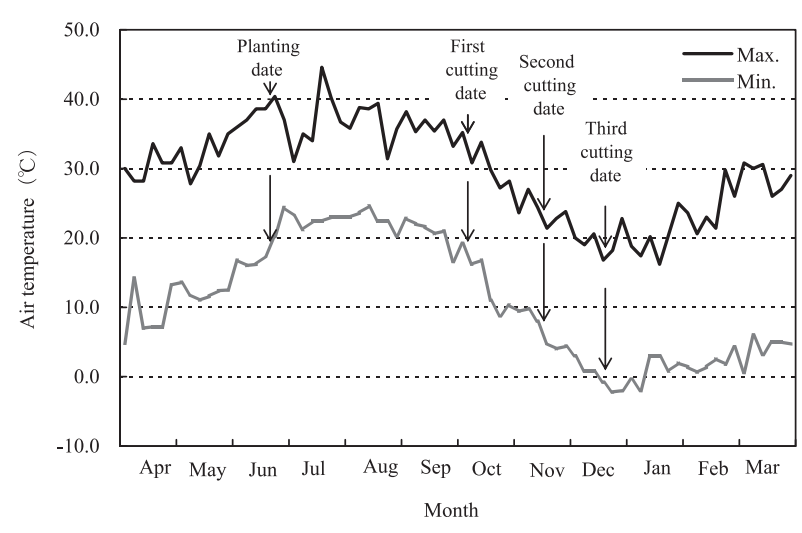

Fig. 1. Maximum and minimum air temperatures at 5-day intervals during the experimental period in the plastic greenhouse in which Chrysanthemum mother plants were grown.

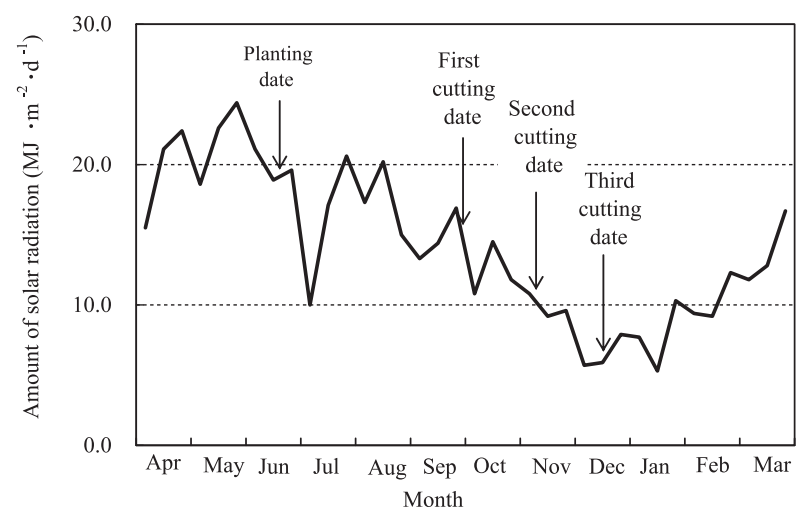

Fig. 2. Solar radiation at 10-day intervals during the experimental period.

$20^{\circ} \mathrm{C}(7: 00-19: 00)$ and $12.5^{\circ} \mathrm{C}(19: 00-7: 00)$ in ambient daylight. The minimum air temperature in the plastic greenhouse in which mother plants were grown exceeded $20^{\circ} \mathrm{C}$ from planting (June 24) to late September, and the maximum air temperature in the same period was 30 $40^{\circ} \mathrm{C}$ (Fig. 1). The minimum air temperature on the first cutting date (September 30 ) was above $15^{\circ} \mathrm{C}$, and those on the second and the third cutting dates fell below $10^{\circ} \mathrm{C}$. Solar radiation decreased gradually from September to December, and increased again from mid-January to March (Fig. 2). From the day of planting, the plants received night-break treatment from 22:00 to 3:00 using $75 \mathrm{~W}$ incandescent lamps for five weeks to inhibit flower bud induction. We recorded the stem length and number of leaves on rooted cuttings at the time of planting and five weeks after planting.

\section{Results}

The increase in stem length (ISL) from the date of planting to five weeks after planting for cuttings taken on September 30 ranged from $19.5 \mathrm{~cm}$ ('Kanamaru Fuji') to $28.5 \mathrm{~cm}$ ('Seiko Komei') among the cultivars (Table 1). The ISL for cuttings taken on November 10 and December 14 ranged from $18.0 \mathrm{~cm}$ ('Sanyo Ogon') to $25.0 \mathrm{~cm}$ ('Kanamaru Fuji'), and from $24.0 \mathrm{~cm}$ ('Sanyo 
Ogon') to $31.0 \mathrm{~cm}$ ('Seiko Komei'), respectively. When the ISL from the first cutting date (September 30) was set at 1.0 in each cultivar, ISL ratios from the second

Table 1. Increase in stem lengths (ISL) of rooted cuttings of ten Chrysanthemum morifolium cultivars grown at constant temperatures of $20^{\circ} \mathrm{C}(7: 00-19: 00)$ and $12.5^{\circ} \mathrm{C}(19: 00-7: 00)$ five weeks after planting. The cuttings were planted on October 14 (cuttings taken on September 30), November 24 (cuttings taken on November 10), and December 28 (cuttings taken on December 14).

\begin{tabular}{|c|c|c|c|}
\hline \multirow{2}{*}{ Cultivar } & \multicolumn{3}{|c|}{ Increase in stem length $(\mathrm{cm})$} \\
\hline & $30 / \mathrm{Sep}^{2}$ & $10 / \mathrm{Nov}$ & 14/Dec \\
\hline Chikushi no Tsuki & $21.5 \mathrm{gh}^{\mathrm{y}}$ & $19.6 \mathrm{ij}$ & $25.0 \mathrm{~d}$ \\
\hline Jinba & $27.8 \mathrm{bc}$ & $23.5 \mathrm{ef}$ & $29.0 \mathrm{~b}$ \\
\hline Kanamaru Fuji & $19.5 \mathrm{ij}$ & $25.0 \mathrm{~d}$ & $29.5 \mathrm{ab}$ \\
\hline Miyoshino & $20.0 \mathrm{hi}$ & $22.0 \mathrm{fg}$ & $29.5 \mathrm{ab}$ \\
\hline Sanyo Ogon & $21.0 \mathrm{gh}$ & $18.0 \mathrm{j}$ & $24.0 \mathrm{e}$ \\
\hline Seiko Komei & $28.5 \mathrm{ab}$ & $23.0 \mathrm{ef}$ & $31.0 \mathrm{a}$ \\
\hline Seiko no Aki & $25.3 \mathrm{~d}$ & $22.0 \mathrm{fg}$ & $26.0 \mathrm{~cd}$ \\
\hline Seiko no Makoto & $23.0 \mathrm{ef}$ & $25.0 \mathrm{~d}$ & $30.0 \mathrm{a}$ \\
\hline Syuho no Chikara & 19.8 hij & $19.5 \mathrm{ij}$ & $30.0 \mathrm{a}$ \\
\hline Yukihime & $20.8 \mathrm{gh}$ & $20.0 \mathrm{hi}$ & $27.5 \mathrm{bc}$ \\
\hline \multirow[t]{3}{*}{ Analysis of variance ${ }^{\mathrm{x}}$} & \multicolumn{3}{|c|}{ Cultivar $(\mathrm{A})^{* *}$} \\
\hline & \multicolumn{3}{|c|}{ Cutting date $(\mathrm{B})^{* *}$} \\
\hline & \multicolumn{3}{|c|}{$\mathrm{A} \times \mathrm{B}^{* *}$} \\
\hline
\end{tabular}

${ }^{z}$ Cutting date (day/month).

y Mean separation by Tukey's HSD test, $5 \%$ level.

$\mathrm{x} * *$ indicates significant at $P<0.01$.

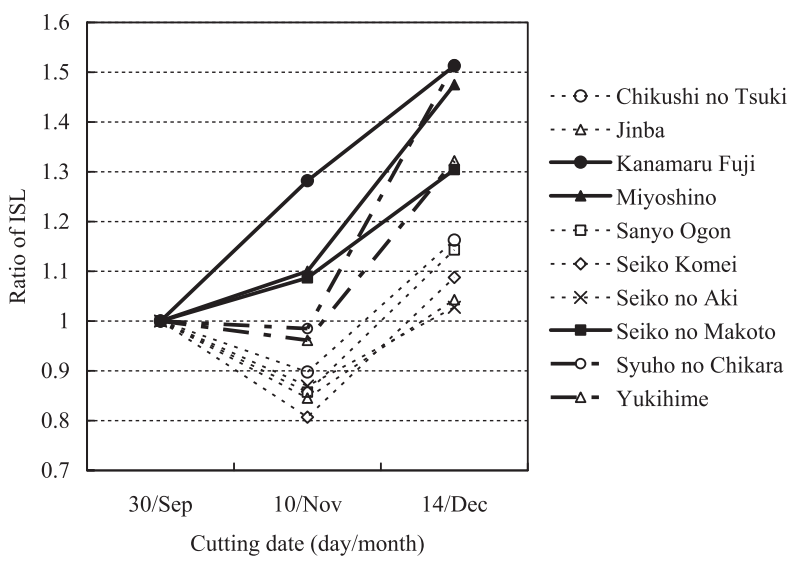

Fig. 3. Ratio of ISL of rooted cuttings of ten Chrysanthemum morifolium cultivars grown at constant temperatures of $20^{\circ} \mathrm{C}$ (7:00-19:00) and $12.5^{\circ} \mathrm{C}$ (19:00-7:00) five weeks after planting planted on October 14 (cuttings taken on September 30), November 24 (cuttings taken on November 10), and December 28 (cuttings taken on December 14). Each point indicates the ratio of ISL of cuttings taken on the second and third cutting dates when the ISL of the first cutting date is set at 1.0. cultivars whose ISL ratio gradually increased from the first cutting date to the third cutting date; $--\cdots$, cultivars whose ISL ratio did not differ significantly between the first and second cutting dates but subsequently increased from the second cutting date to the third cutting date; $\cdots \cdot$, cultivars whose ISL ratio decreased from the first cutting date to the second cutting date and increased from the second cutting date to the third cutting date. and third cutting dates are shown in Figure 3. For five cultivars ('Chikushi no Tsuki', 'Jinba', 'Sanyo Ogon', 'Seiko Komei', and 'Seiko no Aki'), the ISL ratios were below 0.9 for the second cutting date and above 1.3 for the third cutting date. For two cultivars ('Shuho no Chikara' and 'Yukihime'), the ISL ratios for the first and second cutting dates were not significantly different (see Table 1) and subsequently increased above 1.3 for the third cutting date (the difference between the ISL of the second and third cutting dates was significant). In contrast, the ISL ratios of three cultivars ('Seiko no Makoto', 'Kanamaru Fuji', and 'Miyoshino') increased progressively from the first cutting date to the third cutting date.

The ISL of the rooted cuttings treated with $2.5^{\circ} \mathrm{C}$ for six weeks and that of untreated controls, both of which were planted on October 14 and November 28, are shown in Figure 4. The ratios of ISL of rooted cuttings treated with low temperatures to that of untreated cuttings were above 1.0 in all cultivars for both planting dates. The highest ISL ratio of the rooted cuttings planted on October 14 was 1.63 for 'Shuho no Chikara'. Other cultivars with high ISL ratios were 'Chikushi no Tsuki' (1.42), 'Kanamaru Fuji' (1.44), and 'Miyoshino' (1.49). The lowest ISL ratio was 1.05 for 'Seiko Komei'. The
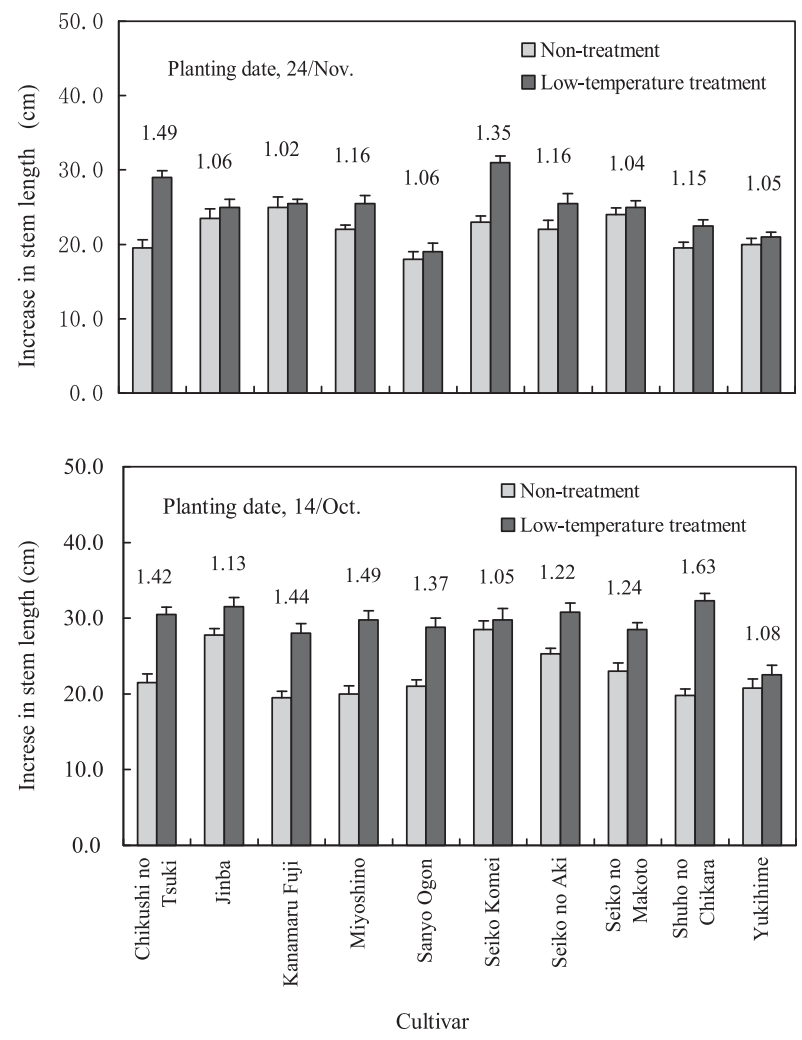

Fig. 4. ISL of rooted cuttings of ten Chrysanthemum morifolium cultivars treated at $2.5^{\circ} \mathrm{C}$ for six weeks (right bars) and untreated controls (left bars) planted on October 14 and November 28. Numbers above each pair of bars indicate the ratio of ISL of rooted cuttings receiving low temperature treatment to ISL of untreated cuttings. Vertical bars indicate SE $(n=5)$. 

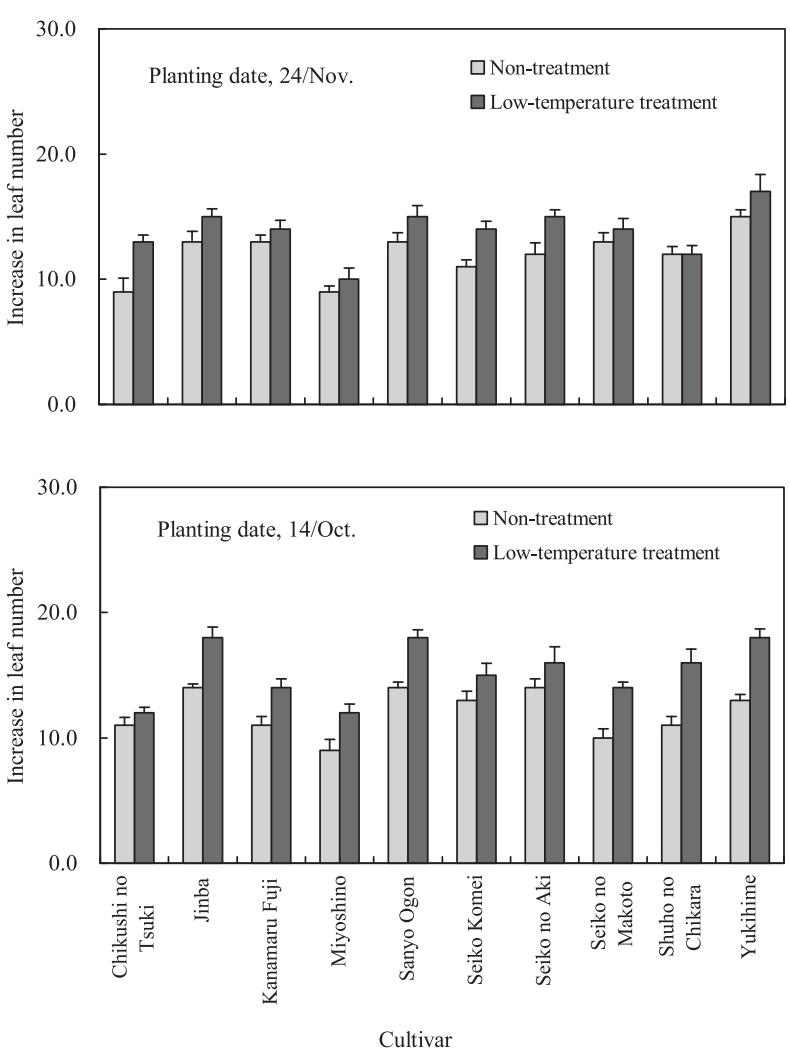

Fig. 5. ILN of rooted cuttings in ten Chrysanthemum morifolium cultivars treated at $2.5^{\circ} \mathrm{C}$ for six weeks (right bars) and untreated controls (left bars) planted on October 14 and November 28. Vertical bars indicate SE $(n=5)$.

ISL ratios of the rooted cuttings planted on November 24 were lower than those of cuttings planted on October 14 in all cultivars except 'Chikushi no Tsuki' and 'Seiko Komei'. In these two cultivars, the ISL ratios were 1.49 and 1.35 , respectively, higher than those of the other cultivars. The lowest ISL ratio was 1.04 for 'Seiko no Makoto'.

The increase in leaf number (ILN) of the rooted cuttings from the date of planting to five weeks after planting on October 14 and November 24 was also recorded (Fig. 5). The ILN of the rooted cuttings receiving low temperature treatment planted on October 14 was higher than that of untreated cuttings in all cultivars. Similarly, the ILN of rooted cuttings given low temperature treatment planted on November 24 was greater than that of untreated cuttings in all cultivars except 'Shuho no Chikara'.

The mean internode length of the rooted cuttings treated with low temperatures was higher than that of untreated cuttings planted on October 14 in seven cultivars; however, the mean internode length of 'Jinba', 'Seiko Komei' and 'Yukihime' was shorter than that of untreated cuttings (Fig. 6).

\section{Discussion}

Garner and Allard (1920) described that in the growth cycle of photoperiodic plants, temperature is the most

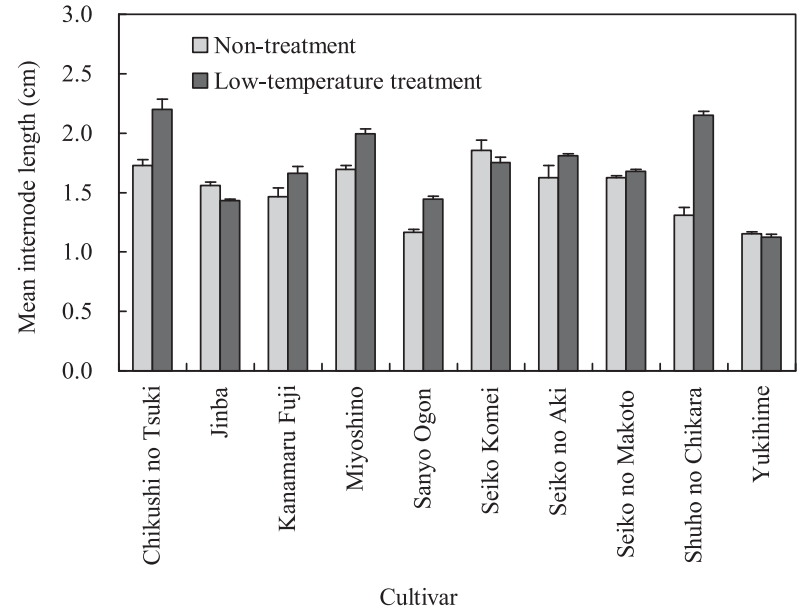

Fig. 6. Mean internode length of rooted cuttings of ten Chrysanthemum morifolium cultivars treated at $2.5^{\circ} \mathrm{C}$ for six weeks (right bars) and untreated cuttings (left bars) five weeks after planting planted on October 14. Vertical bars indicate SE $(\mathrm{n}=5)$.

important modifying factor. Vince and Mason (1957) reported that in Chrysanthemum the reduction of internode length occurred before rosette formation under low temperatures and short days. In addition, flowering is delayed by exposure to high temperatures $\left(35^{\circ} \mathrm{C}\right)$ for as long as 30 days (Schwabe, 1950). Japanese Chrysanthemum 'Okayama Heiwa' plants which were not exposed to low temperatures, or were exposed for a shorter period, formed rosettes under low night temperature conditions, while those exposed for longer periods elongated and flowered normally (Konishi, 1975). The factors responsible for rosette induction and the degree of low temperature exposure required to break the rosette stage seem to vary between cultivars (Okada, 1959). The Japanese cultivars 'Okayama Heiwa', 'Shinn Toa', 'Uchusen', and 'Tama Orihime', in which environmental factors inducing rosette formation have been investigated previously, formed rosettes readily in autumn and winter (Konishi, 1975, 1980; Okada, 1963).

In the present study, it was established that a constant night temperature of $12.5^{\circ} \mathrm{C}(19: 00-7: 00)$ reduced the internode length or induced rosette formation in rooted cuttings taken from mother plants exposed to high temperatures for an extended period and subsequently exposed to low temperatures less than $15^{\circ} \mathrm{C}$ in accordance with the findings of Konishi (1980). Regarding the relationship between the date on which cuttings were taken from mother plants and ISL of the rooted cuttings, the ten cultivars used in the experiments could be divided into three groups based on ISL ratios of rooted cuttings propagated in late-September, midNovember, and mid-December. In five of the ten cultivars studied, the ISL of rooted cuttings taken in mid-November was significantly reduced compared with those taken in late-September, but subsequently the ISL increased in cuttings taken in mid-December compared 
with that of the mid-November cuttings. In two cultivars, the ISL of rooted cuttings taken in mid-November was not significantly different from that of cuttings taken in late-September, and subsequently the ISL increased in rooted cuttings taken in mid-December. In the other three cultivars, the ISL of the rooted cuttings gradually increased from those taken in late-September to those propagated in mid-December. These mother plants did not always exhibit typical rosette formation, and internodes of the lateral shoots slowly elongated in midNovember at a low temperature below $10^{\circ} \mathrm{C}$ in a plastic greenhouse, whereas only mother plants of 'Shuho no Chikara' formed perfect rosettes.

It is considered that the first group of cultivars may belong to the type of cultivars that Okada (1959) and Konishi $(1975,1980)$ investigated. The capability for stem elongation in these cultivars might be lowest at around mid-November when mother plants were exposed to extended high temperature and subsequently exposed to low temperature below $15^{\circ} \mathrm{C}$. Cathey (1954) and Okada (1959) reported that Chrysanthemum plants acquired a rosette tendency under low temperatures $(10$ $15^{\circ} \mathrm{C}$ ) even under long-day conditions. Thereafter, the capability for stem elongation in rooted cuttings was recovered after mother plants were exposed to low temperatures below $10^{\circ} \mathrm{C}$. This is indicated that the stem elongation capability of these cultivars might be satisfied by the low temperature requirement at around midDecember.

In the third group of cultivars, these mother plants were not exposed to low temperature below $15^{\circ} \mathrm{C}$ until at least mid-October. This result indicates that exposure of mother plants to high temperatures might directly reduce the stem elongation ability of plants compared with rooted cuttings taken from mother plants exposed to low temperatures. However, because there were 41 days from the first cutting date (September 30) to the second cutting date (November 10), the possibility of greater reduction of ISL during this period than that of rooted cuttings taken from mother plants in lateSeptember cannot be discounted, because the mother plants were exposed to low temperatures below $15^{\circ} \mathrm{C}$ from mid-October to mid-November. It is important to determine when the capability for stem elongation is most reduced. Nevertheless, it is satisfactory to consider that the stem elongation ability of these cultivars might be recovered progressively after mother plants are exposed to cool temperatures $\left(10-20^{\circ} \mathrm{C}\right)$ for a short period. It is hypothesized that the second group of cultivars might represent an intermediate ecotype between the first and third groups.

It is important to note that the third group of cultivars comprises autumn-flowering cultivars of Japanese Chrysanthemum. Rooted cuttings taken from mother plants of these cultivars may not form a rosette and grow faster than those of other types of cultivars in autumn and winter. In addition, cuttings can be easily taken from mother plants growing in a greenhouse at a low ambient low temperature. It is recommended that this type of cultivar should be used for parents when breeding nonrosette-forming cultivars and may be suitable for yearround cut flower production.

From the results above, the stem elongation ability of Japanese autumn-flowering cultivars is considered to be reduced by either of two types of temperature-related factors; high temperature plus subsequent low temperature below $15^{\circ} \mathrm{C}$, as Konishi (1980) described; or high temperature only or high temperature plus a subsequent short period of low temperature. The rosette-type development of shoots was recovered by lowtemperature treatment of rooted cuttings taken from mother plants in September to October. The effect of low-temperature treatment on the October 14 planting date was higher than that on cuttings planted on November 24 in all but two cultivars. The reason for this may be that the stem elongation ability of rooted cuttings taken from mother plants in mid-August might be higher than those taken from mother plants in lateSeptember; low temperature treatment of the former rooted cuttings might be more effective than that of laterpropagated cuttings; however, in the present study, both of the low-temperature treatments of rooted cuttings increased stem length compared with untreated cuttings. These results support the view that exposure to low temperatures hastens stem elongation, leafing and flower bud initiation as reported by Schwabe (1950). Conversely, long-term exposure to high temperatures directly reduces the capability for stem elongation in autumn-flowering cultivars. The growth stage at which the reduction of stem length and decrease in leaf number occurs (before inducing the rosette stage in some cultivars) could be termed "the preliminary rosette induction stage".

The ratio of ISL in rooted cuttings receiving lowtemperature treatment to that of untreated cuttings might be an indicator to evaluate the low temperature requirement for recovering stem elongation ability. In some cultivars, low-temperature treatment did not increase the mean internode length compared with that of cuttings not exposed to low temperatures. The reason for this is that the rate of leafing was faster than the rate of internode elongation in these cultivars. Rather than the mean internode length, the stem length and leaf number should be measured to evaluate the extent of 'the preliminary rosette induction stage'.

\section{Literature Cited}

Cathey, H. M. 1954. Chrysanthemum temperature study. A. Thermal induction of stock plans of Chrysanthemum morifolium. Proc. Amer. Soc. Hort. Sci. 64: 483-491.

Garner, W. W. and H. A. Allard. 1920. Effect of relative length of day and night and other factors of the environment on growth and reproduction in plants. Jour. Agr. Res. 18: 553606.

Konishi, K. 1975. Rosetting prevention in chrysanthemum by 
chilling the rooted cuttings. J. Japan. Soc. Hort. Sci. 44: 286293 (In Japanese with English abstract).

Konishi, K. 1980. On rosetting of chrysanthemum plants. J. Japan. Soc. Hort. Sci. 49: 107-113 (In Japanese with English abstract).

Machin, B. and N. Scopes. 1978. Chrysanthemums, year-round growing. Blanford Press, Dorset, England.

Mason, D. T. and D. Vince. 1958. The pattern of growth in chrysanthemum as a response to changing seasonal environment. Advances in Hort. Sci. and their Appl. 2: 374 383.

Okada, M. 1959. On resetting of suckers and measures for breaking the rosetting in chrysanthemum. J. Japan. Soc. Hort. Sci. 28: 209-220 (In Japanese with English abstract).
Okada, M. 1963. Studies on flower bud differentiation and flowering in chrysanthemums. Ph. D. Thesis. Tokyo Univ. Education Agric. Bull. 9 (In Japanese with English abstract).

Schwabe, R. H. 1950. Factors controlling flowering of the chrysanthemum. I. The effects of photoperiod and temporary chilling. J. Exp. Bot. 1: 329-343.

Tanigawa, T., A. Yamada, T. Suyama, T. Matsuno and T. Kunitake. 2007. Increase in stem length in long days and number of leaf in short days in the stage of transition from rosette phase to juvenile phase in chrysanthemum cultivars. J. Japan. Soc. Hort. Sci. 6 (Suppl. 2): 358 (In Japanese).

Vince, D. and D. T. Mason. 1957. Low temperature effects on intenode extention in Chrysanthemum morifolium. J. Hort. Sci. 32: 199-209. 